\title{
Therapy-relevant factors in adult ADHD from a cognitive behavioural perspective
}

\author{
Patricia Elizabeth Newark · Rolf-Dieter Stieglitz
}

Received: 29 December 2009/Accepted: 22 March 2010/Published online: 15 April 2010

(C) Springer-Verlag 2010

\begin{abstract}
Adult individuals with attention-deficit hyperactivity disorder (ADHD) have been suffering from this neurobiological and highly heritable disorder chronically since childhood. Resulting from their longstanding neuropsychological impairments, such as attentional problems, emotional instability, and disinhibition, they are familiar to a multiplicity of negative life outcomes and underachievement. Furthermore, a large part of this population suffers from psychiatric comorbidity. This accumulation of negative experiences has an impact on therapy-relevant factors such as the individual's self-esteem, self-efficacy, development of core beliefs/schemas, and coping strategies. Based on negative beliefs about the self, individuals confronted with difficult situations develop maladaptive coping strategies, for instance avoidance and procrastination. These strategies lead to maintenance and reinforcement of maladaptive beliefs, and as such they acquit themselves as schema-confirming. Captured in this vicious cycle, the individual sees her negative view of the self confirmed. The purpose of this paper is to illuminate these interactive factors that influence the aforementioned cycle in order to emphasize the cognitive behavioural interventions tailored to those factors on the basis of latest research. Furthermore, the authors want to attract notice to the resources people with ADHD are said to have, namely creativity and resilience. These postulated resources could be therapy-relevant by creating positive beliefs about the self, hence improving coping skills and breaking the vicious circle of negative appraisal. Taking into account personal resources and their fostering may be an important
\end{abstract}

P. E. Newark $(\bowtie) \cdot$ R.-D. Stieglitz

Psychiatric Outpatient Department, University Hospital Basel, Petersgraben 4, 4021 Basel, Switzerland

e-mail: patricia.newark@upkbs.ch fundament for the treatment plan of adult ADHD. Information on the current state of research and theoretical approaches concerning the below-mentioned key words was gathered through MEDLINE, PsycINFO, PSYNDEXplus, and PubMed databases.

Keywords Adult attention deficit hyperactivity disorder (ADHD) - Cognitive behavioural psychotherapy ·

Self-esteem · Self-efficacy · Core beliefs - Schemas . Coping strategies $\cdot$ Resources

\section{Introduction}

ADHD in adulthood implies suffering from this neurobiological and highly heritable disorder chronically since childhood (Murphy 1998; Ramsay and Rostain 2008). As a result of their longstanding neuropsychological impairments, such as attentional problems, emotional instability, disorganized behaviour, insufficient self-regulation, and disinhibition, they are supposed to be familiar to a multiplicity of negative life outcomes and underachievement. Comorbidity must be named as possible aggravating circumstance given that $70-75 \%$ of adults with ADHD enter treatment with at least one additional psychiatric disorder (most prevalently anxiety disorder, depression, or substance use disorder) (Biederman 2004; Shekim et al. 1990; Wilens et al. 2002).

Various areas of an individual's life with ADHD are affected, which manifests itself in interpersonal, academic, and vocational difficulties. This accumulation of negative experiences affects the formation of the individual's selfesteem and self-efficacy (Ramsay and Rostain 2008). Moreover, they have an impact on the development of core beliefs/schemas (e.g. defectiveness, failure). Based on 
negative beliefs about the self and the own competences, individuals confronted with stressful events develop maladaptive coping strategies (dysfunctional behaviour) such as avoidance and procrastination. Insidiously as they are, these strategies lead to maintenance and reinforcement of maladaptive beliefs, and as such they acquit themselves as schema-confirming. Captured in this vicious cycle, the individual experiences disappointments over and over again, confirming her negative view of the self.

On the other hand, adults with ADHD are said to be especially creative and resilient (Young 2005; Hallowell and Ratey 1994) and to possess strengths and resources. If the resources postulated are identified and acknowledged, they could be therapy-relevant by creating positive beliefs about the self and the own abilities. This in turn would improve coping skills and break the vicious cycle of negative appraisal.

The aim of this paper is to illuminate these cohesive and interactive factors that influence the aforementioned cycle in order to emphasize the cognitive behavioural interventions tailored to those factors on the basis of latest research.

Taking into consideration that a lot of different factors can be significant for the psychotherapy of ADHD in adulthood, we want to focus only on those immanent factors that already existed before treatment, such as the patient's inner psychic experiences with respect to the image of herself and her own capabilities. Of further interest is the resulting impact on coping strategies as well as resources that can help improve coping strategies.

These factors have a specific importance in adults with ADHD, as troubled with their disorder and associated negative life outcomes, these patients enter psychotherapy with a negatively colored perspective of the self. If identified by the therapist, these factors are potentially of paramount importance for psychotherapy.

\section{Methods}

Information on the current state of research and theoretical approaches concerning the below-mentioned key words was gathered through MEDLINE, PsycINFO, PSYNDEXplus, and Pubmed databases. The time span ranged from 1980 to November 2009. The search was conducted using the following key words: adult attention deficit hyperactivity disorder (ADHD), cognitive behavioural therapy, psychotherapy, self-esteem, self-efficacy, core beliefs, belief system, schemas, coping strategies, resources, creativity, and convergent/divergent thinking.

We also scrutinized reference lists of articles and used citation searching for all articles that referred to our key words. Articles were included if they addressed topics such as cognitive behavioural approaches for adult ADHD, cognitive behavioural therapeutic concepts (concerning ADHD and self-esteem, self-efficacy, core beliefs, coping strategies, resources), schema therapeutic approaches, or basic principles of theory relating to either self-esteem, self-efficacy, core beliefs, schemas, coping strategies, or resources.

The subsequent text consists of the following sections: Core beliefs/schemas, self-esteem, self-efficacy, coping strategies, and resources. Each section is further divided into four subsections, composed of definition, relevance for adult ADHD, empirical studies, and specific therapeutic interventions and their significance.

\section{Core beliefs/schemas}

\section{Definition}

The origins of the word schema trace back to Piaget (1948), who defined schema as a mental representation of an associated set of perceptions, ideas, and/or actions. Piaget considered schemata to be the basic building blocks of thinking. Schemata help us adapt to new situations, as the individual assimilates contextual information and accommodates existing structures. In turn, the existing structures affect the individual's ensuing assimilation.

Beck's (1967) notion of schema was "a structure for screening, coding and evaluation of the stimuli that impinge on the organism. On the basis of schemas, the individual is able to [...] categorize and interpret his experiences in a meaningful way" (p. 283). In his cognitive therapy, Beck $(1976,1995)$ applied the term "core belief" to describe schemas. He assumed that beginning in childhood, every human being develops certain beliefs about the self, the environment, and the future (also known as cognitive triad, Beck 1967). The deepest beliefs, the core beliefs, are fundamental and deeply enrooted, often not even pronounced to oneself. These core beliefs are considered by the person as absolutely true and unchangeable. Core beliefs can be active most of the time or can be activated when the person feels depressed. Once activated, all situations suffer the bias of this belief, despite actual evidence against it. Moreover, the person tends to focus selectively on information that supports her beliefs, while ignoring or devaluating conflicting information.

In recent years, schema therapy (Young et al. 2003) has been developed, which emanates from recurring negative experiences and negative feedback from the environment that lead to specific, negative thoughts about oneself and the world. Those thoughts are anchored in so-called schemas or maladaptive schemas (Young et al. 2003). Young defines schemas as "broad, pervasive themes regarding oneself and one's relationship with others, developed 
during childhood and elaborated throughout one's lifetime, and dysfunctional to a significant degree" (p. 38-39). Schemas emerge from central emotional needs that were left unmet in childhood. Based on the idea of the existence of five basic and universal emotional needs, schema therapy tries to help patients meet their emotional needs in an adaptive way.

\section{Relevance for adult ADHD}

From a very early age onwards, individuals with ADHD experience multiple difficulties in several domains of life, which affect their performance (e.g. school, work) as well as their interactions with significant others.

A "difficult child" will be confronted with more negative feedback than an inconspicuous child and therefore may develop a cognitive schema such as defectiveness. Based on this schema and the associated negative beliefs, the child will make choices and gain schema-confirming experiences on cognitive, emotional, and behavioural levels.

Typical maladaptive schemas (see Ramsay and Rostain 2003) in adults with ADHD are above all defectiveness ("I'm basically inadequate"), failure ("I've not fulfilled my potential"), and insufficient self-control ("I cannot rely on myself to do what I need to") (Ramsay and Rostain 2003). Moreover, the affected individuals are prone to cognitive distortion (Beck 1963) such as overgeneralization or comparative thinking. Self-defeating behaviour patterns ("compensatory strategies"), namely avoidance and procrastination, are of utmost importance to keep alive the maladaptive schemas and cognitive distortions. In order to break these compensatory strategies, the focus of treatment must be directed towards the belief system (McDermott 2000; Ramsay and Rostain 2008). Ramsay and Rostain (2008) highlight the importance of working on the avoidance behaviour, which is highly resistant to extinction.

Even though negative thinking is not the cause of ADHD, it can lead to maintenance and reinforcement of compensatory strategies, which can perturb the handling of ADHD-related symptoms and problems.

\section{Studies}

The conducted Web search (see section on methods) using the key words "adult ADHD", "schemas", "schema therapy", and "belief system" found no studies that specifically focus on the therapy of schemas and/or the belief system in adults with ADHD.

Specific therapeutic interventions and their significance

According to Ramsay and Rostain (2008), Cognitive Behavioural Therapy (henceforth "CBT") for adult ADHD implies a case conceptualization in which learning history, negative beliefs, resulting schemas, and self-defeating behaviour are being detected. To capture the automatic thoughts, the Daily Thought Record (DTR) (Beck et al. 1979) is completed. Aim of this record is to help the patient detect difficult situations and understand the cohesion between cognitions, emotions, and behaviour. With the help of a list that specifies cognitive distortions, automatic thoughts can be classified in a systematic way. By identifying these distortions, the patients can recognize that reflexive thinking can be misrepresented by ignoring or exaggerating information. In the end positive, alternative thoughts are being developed.

The deeply enrooted schemas and beliefs are not as easily identified and modified as automatic thoughts. One strategy is the downward arrow technique (Burns 1980), where the patient is instigated to consider the relations of automatic thoughts and the underlying beliefs.

On the other hand, it is crucial for the patients to make new experiences and therefore to challenge negative beliefs. Hence, behavioural experiments are not only important to practice coping skills, but also to modify their belief system. It must be considered that for patients with moderate to severe ADHD, the work on maladaptive schemas might require a longer term CBT (Ramsay and Rostain 2008).

Mc Dermott (1999) adopted cognitive strategies to change long existing dysfunctional beliefs and named it the SPEAR (Stop, Pullback, Evaluate, Act, and Revaluate) technique. The technique consists of the following steps: 1. Stop: When it comes to the activation of emotional stressful beliefs, the patient might say aloud, "Stop" or temporary leave the situation. 2. Pullback: Continuing to deactivate the predominant belief and try to acquire an emotionally more neutral condition. Helpful strategies therefore might be distraction, relaxation, or imagery techniques. 3. Evaluate: Once in a calmer state, patients can start evaluating the situation with problem-solving skills (CBT) such as rational responding, generating alternative hypotheses, and developing multiple options for solutions. 4. Act: Patients start to resolve the problem by relying on their evaluation. 5. Revaluate: After a small action, patients are due to reassess their emotional state before acting further in order to have more control over their mood.

According to McDermott (2000), cognitive therapy for adults with ADHD should put a strong emphasis on belief change, as negative cognitions, emotions, and beliefs can enhance typical ADHD features, such as distractibility and impulsivity. Focusing and working on the belief system may help manage, affect, and increase the effectiveness of psychotherapy in adult ADHD.

Bramham et al. (2009) applied Beck's cognitive model (1976) on negative cognitions, thus indirectly on core 
beliefs in adults with ADHD. The main techniques consist of identification of negative thoughts, automatic thoughts, and thinking errors by keeping a thought diary. Subsequently, the patient works on challenging and replacing negative cognitions with alternative, more helpful ones.

Identifying and modifying negative cognitions, or even the core beliefs, is a crucial part of Cognitive Behavioural Therapy (henceforth "CBT") in adult ADHD when it comes to facilitating the work on compensatory strategies (e.g. procrastination, see subsection on coping strategies) or low self-esteem (see subsection on self-esteem). Moreover, it can help foster existing resources and resilience by showing the patient alternative ways to appraise the self, the environment, and the future (cognitive trias, Beck (1976).

\section{Self-esteem}

\section{Definition}

Self-esteem reflects a subjective appraisal concerning the personal worth and ability that is fundamental to an individual's identity (Asendorpf 1996). Rosenberg (1965) defined self-esteem as a favourable or unfavourable attitude towards the self (p. 15). The very popular use of the term self-esteem, both in popular language and in psychology, makes it difficult to distinguish between the multitudes of expressions. At this point, three of the most relevant terms are presented.

Global self-esteem (Trait Self-Esteem) refers to a personality variable that represents the way people generally feel about themselves. It has been shown to be a stable variable throughout adulthood, with a probable genetic component related to temperament and neuroticism (Neiss et al. 2002).

Feelings of Self-Worth (State Self-Esteem) differ from global self-esteem by being temporary. They stand for the self-evaluative reactions to significant events.

Self-Evaluations or self-appraisal (Domain Specific Self-Esteem) stands for the way individuals evaluate their abilities and attributes. This kind of self-esteem is specific to a domain.

In this paper, the focus lies on global/general self-esteem, unless mentioned otherwise, as the authors want to follow the impact of a stable/trait variable on an individual's life.

So what does self-esteem consist of? At the core of selfesteem lie the central beliefs about oneself (see subsection on core beliefs/schemas), which have developed from life experiences. If these beliefs consist of negative validation, low self-esteem emerges. Positively colored self-esteem may contain statements about oneself such as "I'm good" or "I'm worthwhile", while people with low self-esteem tend to make statements such as "I'm stupid" or "I'm incapable." Low self-esteem, according to Rosenberg
(1979), "means that the individual lacks respect for himself, considers himself unworthy, inadequate, or otherwise seriously deficient as a person” (p. 54).

\section{Relevance for adult ADHD}

Individuals diagnosed with ADHD often start therapy with low self-esteem that has been prevalent for a long time. As a result of their longstanding neuropsychological impairments, such as distractibility, disorganization, emotional instability, or disinhibition, they have not adopted effective coping skills (see Fig. 1) (Ramsay and Rostain 2003; Bramham et al. 2009). Thus, patients with ADHD typically are familiar with many negative life outcomes and underachievement. Interpersonal relations are affected at home and at work, commonly resulting in criticism and rejection. This often leads to reduced self-esteem (Philipsen et al. 2007).

A history of having difficulties in several domains of life, such as problems with education, vocation, relationships, and an increased risk of comorbid psychiatric problems, overshadows the concerned people's life. Due to the aforementioned difficulties, people with ADHD can be vulnerable to negatively appraise certain situations with a pessimistic bias (see Fig. 1). Ramsay and Rostain (2008) found that adults with ADHD are likely to have significantly more negative thoughts, to be less hopeful about the future, and less accepting of themselves then those without ADHD. They also recall having more difficulties and negative experiences in childhood than individuals who are not affected (Faraone and Biederman 2005).

The recurring feeling of failure and underachievement strongly impacts their self-esteem and makes them doubt their own abilities (e.g., "I can't do it"). In line with the self-fulfilling, prophecy failure is expected to happen in the future (e.g., "I'm going to fail again"). Negative cognitions and beliefs may enhance negative emotional reactions to external demands, hence, encourage maladaptive coping strategies such as avoidance and procrastination (e.g., "I'm not in the mood now, I'll do it later"). The consequences are lasting or deteriorating problems, low self-esteem brought on by feeling unable to cope in an effective way, and impact on the emotions (e.g., frustration, anger, anxiety, depression). Once in a negative emotional state, individuals are more likely to evaluate situations negatively, leading to a vicious cycle (see Fig. 1).

\section{Studies}

The subsequent literature describes recent study outcomes, pointing out the impact of cognitive behavioural interventions on symptoms of ADHD and on self-esteem in patients with ADHD. 
Fig. 1 A cognitive behavioural model of adult ADHD (modified from Young and Bramham 2006 and Safren et al. 2005)

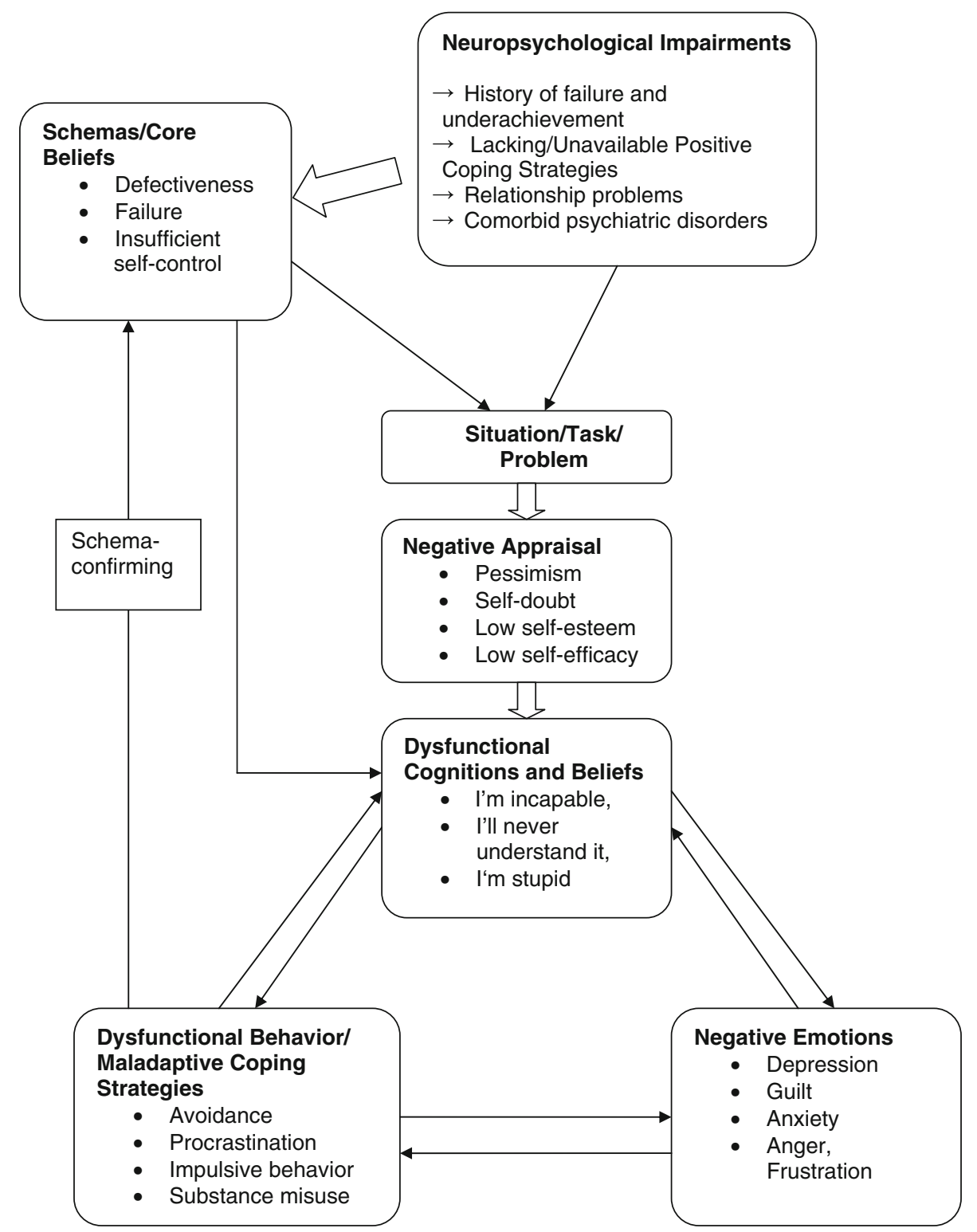

Stevenson et al. (2002) evaluated the efficacy of their Cognitive Remediation Programme (CRP), focussing on ADHD-related problems and low self-esteem. Participants in the CRP and in the control group were either unmedicated or on a stable dose. After treatment, participants of the CRP group reported significant improvements on the ADHD symptom checklist and in self-esteem. At the twomonth follow-up, all treatment effects were maintained or continued to improve.

Stevenson et al. (2003) conducted another study examining a self-directed version of their CRP. The treatment group (CRP) received minimal therapist contact, a self-help book, and weekly telephone contact with coaches. At the end of treatment, self-esteem measures of the CRP group showed significant improvements compared to the self- esteem measures of the wait-listed control group. Treatment gains at the two-month follow-up were only maintained for ADHD symptoms, organizational skills, and trait anger.

Bramham et al. (2009) evaluated a brief CBT group intervention intended to treat comorbid anxiety, depression, low self-esteem, and self-efficacy in adults with ADHD. The CBT/medication group was compared with a medication-only group, which was on the waiting list for the CBT group intervention. Three one-day workshops were held monthly including material from the YoungBramham Programme (Young and Bramham 2006).

At the end of the therapy programme, the CBT group showed significantly greater improvement on measures of knowledge about ADHD, self-efficacy, and self-esteem than the control group. Both groups showed improvement 
in symptoms of anxiety and depression. According to the participants, sharing personal experiences with other adults with ADHD was an important aspect of the intervention. However, there was no follow-up period, and the maintenance of the gains was not investigated.

Wiggins et al. (1999) compared an experimental group attending four 90 -min psychoeducational sessions with a control group who did not receive group treatment. The standard CBT approach served as theoretical background for the experimental group.

The research showed that after treatment adults with ADHD experienced improvements in attention and organization but decreases in measures of self-esteem. After long-standing functional difficulties, they might experience lowered self-esteem when faced with the magnitude of their symptoms in treatment. This descent in self-esteem was hypothesized to be temporary, yet follow-up measures were not collected.

Specific therapeutic interventions and their significance

In her cognitive remediation programme, Stevenson (2002) applies cognitive strategies for improving self-esteem. Participants learn to identify automatic thoughts, challenge negative statements, and evaluate judgements. By praising themselves for achievements, the focus is set on the strengths of the person.

Wiggins et al. (1999) base their intervention on the TFA model (Hutchins and Vaught 1997), which offers a schema of thoughts (T), feelings (F), and actions (A). The TFA model was used to enable the patient and the therapist to organize information about behaviour, to evaluate probable outcomes, and finally to change the behaviour.

Young and Bramham (2006) emphasize the importance of the CBT model in adults with ADHD. As for coping with negative thoughts, patients first become acquainted with the connections between mood, thoughts, and behaviour.

Typical thinking errors of people with ADHD (adapted from Beck 1963) are introduced to the patients, and then they start identifying their own negative thoughts, automatic thoughts, and thinking errors by maintaining a thought diary (to record situations, feelings, thoughts, cognitive challenges, and to identify thinking errors). Patients familiarize themselves with negative thinking, and in a second step, they work on challenging and replacing negative thoughts with alternative, more helpful ones.

Non-helpful behaviour, such as avoidance, leads to reduced confidence/self-esteem. Hence, the programme includes strategies to develop confidence and to restart activities they have avoided.

According to the evaluation of the participants, sharing personal experiences with other adults with ADHD was also an important aspect of the intervention.
The cognitive behaviourally oriented group rehabilitation programme of Virta et al. (2008) includes one session about self-esteem that focused on negative beliefs, techniques for improving self-esteem, and reformulating negative beliefs. The therapists followed a detailed written manual, published in Finnish (Leskelä et al. 2007).

Likewise, Ramsey and Rostain (2005) highlight that cognitive behavioural interventions and behavioural skills training can help patients develop effective coping strategies for managing symptoms of ADHD and help deal with the demands of life. These interventions may have an impact on dysfunctional thoughts, negative emotions, and therefore on self-esteem.

Although psychoeducation is a general method in psychotherapy, its importance as a possible specific intervention for adult ADHD to start working on self-esteem warrants an elaboration.

Safren (2004) and Wender (1995) consider a clarification of the nature of the syndrome and the associated impairments as an essential first step on the outset of every ADHD treatment. Through a better understanding of these neurocognitive impairments and their effects on executive functioning of daily life, the individual can review important life events in her past through a new perspective. The patient can finally give up feelings of guilt and of selfinflicted underachievement, enabling her to see problems in a more realistic way-as a neurobiological disorder. This constitutes an important onset for building self-esteem.

Bramham (2009) posits that psychoeducation can help people with ADHD repair their self-esteem by creating an understanding about this neurobiological disorder and the associated behaviour. For an outright psychoeducation, Young and Bramham (2006) suggest including information on the aetiology of ADHD, its prognosis, comorbid problems, cognitive deficits, and their manifestations in daily living. Additionally, ADHD-associated factors such as skills deficits and the likelihood of maladaptive coping strategies should be explained.

Increased knowledge and understanding of ADHD may cause a change in attribution of aetiology for the afflicted person's impairments and give her a feeling of control, producing a rise of self-esteem. By acknowledging her limitations, she can develop realistic expectations of performance, which is an achievement of special importance for psychotherapy.

\section{Self-efficacy}

Definition

While self-esteem denotes a personality trait that represents the way one feels about oneself, perceived self-efficacy 
(SE) stands for an individual's beliefs in her capabilities to perform a specific action required to attain a desired outcome. It is the main reason for influencing behaviour (Bandura 1997). In addition, self-efficacy beliefs influence cognitions, emotions, and behaviour and accordingly seem helpful in dealing with stressful conditions.

Schwarzer and Jerusalem (1995) and Sherer el al. (1982) postulated a generalized self-efficacy (GSE) that is characterized by a broad and stable sense of personal competence about coping effectively with diverse stressful situations. While the term perceived self-efficacy is used in a situation-specific manner (Bandura 1997), GSE finds its application in a broader diversity of behaviour and coping outcomes (Luszczynska et al. 2004). GSE appears to be a universal and transcultural construct (Luszczynska et al. 2005; Bandura 2002), which means that it characterizes a basic belief that is innate in all individuals.

\section{Relevance for adult ADHD}

What challenges people meet and how high they set their goals depend on the expectations they have of positive outcome of future actions. Strong SE is related to a positive outcome expectancy of future actions, and, respectively, to less negative outcome expectancy (Bandura 1997). On the other hand, low SE is associated with negative outcome expectancy, which implies an anticipation of obstacles after a behaviour change takes place (forecast of unpleasantness or the necessity to pass on other favourite activities). Thus, strong SE leads to changes in behaviour and is expected to be highly self-regulatory (Luszczynska et al. 2004). De Vellis and de Vellis (2000) found that people with strong self-efficacy seem to select more challenging goals and focus more on opportunities than on obstacles.

Jerusalem and Schwarzer (1992) depicted the role of general self-efficacy as a resource/vulnerability factor. In their study, individuals with high self-efficacy were resistant to stressful situations and feedback about failure, and this characteristic remained stable over time. Appraisals of the situation remained predominantly positive and were treated as challenge.

In contrast to this resistance to stress, subjects with low self-efficacy were especially vulnerable to stressful situational conditions and experiences of failure. They appraised the situation and themselves negatively, felt less challenged, but higher levels of threat and loss. If adults with ADHD experience the feeling of high SE, this would be a great resource for psychotherapy, as they aim for behavioural change, feelings of competency, and the ability to cope with stressful events in an effective way. Unfortunately, a multiplicity of individuals suffering from ADHD hardly experience the feeling of controlling and influencing their life through their actions. They are rather familiar with feelings of demoralization, anxiety, and uncertainty about their future. Frequently, they experience multiple failures in life and underachievement (Safren 2006), which leads to low SE.

Nonetheless, there is evidence to suggest that adults with ADHD have the capability to revaluate or cognitively reframe stressful events (Young 2005). It is peculiar how people with ADHD positively reframe an experienced negative outcome and try to succeed again. This resilience is generally found in individuals with ADHD, a fact that could be traced back to their belief in self-efficacy.

\section{Studies}

Only a few studies explore the relationship of self-efficacy in adults with ADHD. A study by Bramham et al. (2009) showed that the CBT and medication group (group therapy) had significantly greater improvements on measures of self-efficacy in the General Self-efficacy Scale (Schwarzer and Jerusalem 1995) than the control group (medication-only).

The multicultural validation studies of Luszczynska et al. (2005) showed that among patients with gastrointestinal disease, GSE was related to less frequent use of passive coping and more frequent use of active coping with pain. Cancer patients with high GSE frequently applied active coping, planning, positive reframing, humour, fighting spirit, and information seeking. Those patients with low GSE more frequently used coping strategies such as self-blame or behavioural disengagement.

Although the study investigates GSE in patients with physical disorders and not ADHD itself, it is noteworthy that GSE appears to have an impact on coping strategies independently of a specific, physical, or psychiatric disorder. The generality of the GSE construct after Luszczynska et al. (2005) implies its applicability to a variety of domains of human functioning (e.g. adherence to medical recommendations, positive and negative affect, coping with stress). Their research suggests that engagement and maintenance in healthy behaviour as well as recovering after setbacks is more likely in people equipped with a higher GSE. Such a comprehensive view puts a connection of GSE and ADHD in a positive light. Still future research is needed to specifically investigate GSE in adults with ADHD.

In therapy for adult ADHD, a combined treatment (CBT and medication) seems to be superior in enhancing selfefficacy than pharmacotherapy alone. Cognitive behavioural interventions may be of central importance for that purpose. Through CBT, the patients may enhance their confidence in their capabilities of coping and developing strategies to deal with challenges in an active and effective way. 
Specific therapeutic interventions and their significance

Improving self-efficacy starts with people's belief that they can achieve. To encourage the patient to set goals for the future, it is important to first look at the patient's strengths and lifetime achievements (Bramham et al. 2009). For that purpose, a "top ten achievements" list can be used. Further strategies involve the use of social support structures (e.g. family, friends) to help set goals, anticipate potential pitfalls, and have problem-solving strategies readily available (Bramham et al. 2009). Self-reinforcement techniques such as posters or flash cards can be used as reminders of goals and as means to assist with coping strategies. Additionally, the use of an advantages/disadvantages table can be a helpful technique. A very important building block of therapy in adults with ADHD is to establish immediate rewards for success (Bramham et al. 2009). By informing others about her progress, she can get support and encouragement, which invigorates her confidence.

Through the use of CBT, patients should be encouraged to change things and achieve goals on their own instead of avoiding the quarrel with their daily hassle Therapy provides coping techniques that can help the individual reach their goals. With respect to raising self-efficacy, it is of paramount importance that patients feel capable of coping autonomously with obstacles and are able to succeed. Those who are said to "reframe negative outcomes positively and try again" (Young 2005) may have higher SE, which can facilitate the access to therapy. Nevertheless, they may benefit from the structured approach of cognitive behavioural strategies to enhance their problem-solving strategies and sense of achievement.

\section{Coping strategies}

\section{Definition}

Coping strategies refer to the specific efforts, both behavioural and psychological, that people employ to master, tolerate, or minimize stressful events. Two general coping strategies are being distinguished: problem-solving strategies, which are efforts to actively alleviate stressful circumstances, and emotion-focused coping strategies that involve efforts to regulate the emotional consequences of stressful or potentially stressful events (Schwarzer and Jerusalem 1989). Research indicates that individuals use both types of strategies to combat stressful events (Folkman and Lazarus 1980). An additional distinction that is often made in the coping literature is between active and avoidant coping strategies. Active coping strategies are either behavioural or psychological responses designed to change the nature of the stressor itself or how one thinks about it, whereas avoidant coping strategies lead people into activities (such as consuming alcohol) or mental states (such as procrastination) that keep them from directly addressing stressful events. Generally active coping strategies are thought to be better ways to deal with stressful events, whereas avoidant coping strategies appear to be a psychological risk factor for adverse responses to stressful life events (Holahan and Moos 1987).

\section{Relevance for adult ADHD}

Ramsay and Rostain (2008) differentiate between compensations, which are positive coping strategies, and compensatory strategies, which are maladaptive coping strategies.

Adults with ADHD who cope well with the challenges caused by the core symptoms of their impairment (Murphy 1998) employ compensation. For example, a person who often forgets her appointments could ask her friends to call her $1 \mathrm{~h}$ before the appointment as a reminder.

The notion of compensatory strategies refers to compensatory behaviour that maintains and reinforces maladaptive core beliefs and schemas (see 2.1). Avoidance is one of the most common and frequently used compensatory strategies in adults with ADHD (Murphy 1998; Ramsay and Rostain 2003, 2008).

For example, a student faced with an imminent exam experiences negative emotions (anxiety, low mood) and predictions ("I'm going to fail anyway"), so the "failure" schema is reactivated ("I'm stupid"). By procrastinating to read and study, the student protects herself against viewing herself as inadequate and can undergo relief from emotional discomfort (negative reinforcement). She turns towards more pleasurable activities and might cognitively avoid considering the consequences of her evasion and/or procrastination. In the end, the student turns out to be unprepared for the exam and receives low grades, which reinforces her sense of inadequacy ("Now I have proof that I'm stupid and I can't handle college."). Objectively, the student's conclusion is unjustified, given that she never prepared herself sufficiently for the exam. However, because her experience was consistent with her belief system, she considered it a valid confirmation without exploring alternative explanations.

Identifying compensatory strategies and using them to elicit the specific schema/core beliefs are crucial steps in developing a case conceptualization (Ramsay and Rostain 2008).

Compensatory strategies used by adults with ADHD (Ramsay and Rostain 2003) are:

- Anticipatory avoidance/procrastination: Putting off a challenging task because the person anticipates that it 
will be unpleasant and is doubting her own ability to complete it. Rationalization to justify procrastination behaviour.

- Brinkmanship: Waiting to start work until one is up against a deadline. Adrenaline rush associated with the pressure of facing a deadline may serve as a form of self-medication in that the person describes being able to focus better. Disruptive working style.

- Pseudo-efficiency: The person completes many things on the "to-do" list that are low-priority or more attractive. Avoidance of the highest priority tasks.

- Juggling: Taking on new, interesting projects without completing projects already started. Tendency to say "yes" to requests to avoid missing out on something exciting.

\section{Studies}

Coping strategies commonly employed by adults with ADHD were investigated (Young 2005) to evaluate them and gain information about their relationship with cognitive deficits and antisocial personality problems. The ADHD group was compared with a healthy control group regarding coping strategies, impulsivity, attention, and prosocial behaviour. The ADHD group was found to use maladaptive coping strategies such as confrontative, escape-avoidance, and less painful problem-solving strategies. In contrast seems that people with ADHD have the capacity to positively reappraise stressful situations, encouraging them to try again. This kind of resilience may constitute a protective factor.

Young's research suggests that individuals with ADHD have specific deficits in coping and need to learn the application of positive coping skills in stressful situations.

Specific therapeutic interventions and their significance

CBT can assist with developing and practicing effective coping strategies in adults with ADHD. Safren (2006) divides the interventions to develop coping strategies into two types:

- behavioural skills training which implies training in organization and planning as well as managing avoidance.

- cognitive interventions. These include working on dysfunctional cognitions and negative emotions that may emerge from failures and underachievement, which can further reinforce avoidance, procrastination, and distractibility.

Although ADHD is primarily a neurobiological disorder, emerging evidence suggests that a skills-building approach (CBT) has statistically and clinically significant effects for adults with ADHD (Safren 2006).

In the Young-Bramham programme (2006), a distinction is drawn between interventions for emotional-focussed coping (situations that are beyond the patient's control) and instrumental problem-solving (controllable situations).

For last named situations, the five stages of problemsolving are employed to improve problem-solving strategies: (1) identifying and defining the specific problem (2) generating various solutions to the problem (3) evaluating each solution (4) implementing the chosen solution, and finally (5) evaluating success. For situations in which the patients feel beyond their control, emotion-focussed strategies are applied to help the patient manage their feelings. Mood-focussed strategies consist of identifying and challenging negative thoughts, superimposing positive thoughts, and changing behaviour. The technique of superimposing positive thoughts (such as making positive and motivating self-statements) may be very helpful because of the resilience individuals with ADHD are said to have. This may be a "natural" way for them to cope with negative thoughts.

In McDermott's (1999) cognitive therapy treatment guidelines, patients learn basic strategies and techniques for dealing with their dysfunctional thoughts, emotions, and behaviours (compare SPEAR-technique on p. 6). They also learn to develop skills for dealing with comorbid disorders. For that purpose, Becks's cognitive therapy (1995) is applied.

A person who is aware of her available coping competence will appraise stress-relevant situations in a challenging way and become active. The self-perception remains positive, and the person expects to be able to meet situational demands.

Adults with ADHD either adopt helpful coping skills or compensatory strategies. To identify which one is applied, and how self-efficacious they experience themselves, is of great importance for therapy.

Helpful coping skills must be fostered, while compensatory strategies must be abolished. Therapy should allow the patient to make new experiences, to acquire new coping skills, and to achieve realistic goals, so her sense of selfesteem and self-efficacy can thrive. This may involve enhanced coping strategies.

\section{Resources}

Definition

"Strengths" or "potentials" of a person or of the environment are the frequently used synonyms in the literature of resources. Nestmann (1996) defines resources as "finally 
everything what is appreciated by a certain person in a certain situation or is experienced as helpful." The perception of resources can be either subjective (perception of the own person) or objective (perception of the own resources by an observer) (Grawe 1997).

For coping with the daily stressors as well as with special challenges, the perceived subjective resources seem to be crucial (Jerusalem 1990; Frank 2007). In general, all people are said to have resources, and therefore the possibility for personal development and to organize their environment in an advantageous way (Grawe 1998).

The quality of a resource is dependent on its validation and disposability. With regard to content, the following types of resources are distinguished: External, interpersonal, and intrapersonal resources. External resources comprise the social, cultural, and physical environment and are crucial to sustaining health (Cohen et al. 2000; Lopez and Snyder 2004). Interpersonal resources (Karpel and Bauers 1986) refer to relational patterns or characteristics in dyads or bigger systems that limit pathology in relations, respectively, facilitate and enrich living together. The term of intrapersonal resources includes a person's behavioural patterns as well as belief systems that support and help recover health. All aforementioned resources can be stable or variable over time.

\section{Relevance for adult ADHD}

Different internal resources, such as enhanced creativity (Hallowell and Ratey 1994; Weiss 1997) or resilience (Young 2005), are supposed to be characteristic of adults with ADHD. Furthermore, making use of external resources (such as friends, family, coaches, etc.) can be a helpful strategy in building a support system (Young and Bramham 2006; Ramsay and Rostain 2008; Murphy and Gordon 2006). If individuals with ADHD are aware of their resources, they can apply them to deal with impairments and to achieve goals. Moreover, self-efficacy may be invigorated by the belief that one is capable of performing a specific action required to positively influence one's life (see section on self-efficacy). On the other hand, the perception of particular resources may allow adults with ADHD to deal with requirements in different domains of life in a way that is more natural for them (Weiss 1997).

Evidence suggests that adults with ADHD have the capability to revaluate or cognitively reframe stressful events and "try again" (Young 2005). As such, they are said to have the ability to constantly compensate and adapt. Young (2005) points out the adaptive aspect of the syndrome that may be expressed as creative and entrepreneurial personality traits.

These specific attributes may be very important for therapy as people with ADHD are expected to not give up as easily when faced with difficulties and to display high levels of motivation to work on their problems.

Assuming that the vicious circle described in Fig. 1 can be turned to an opposite, positive direction, the following model emerges (see Fig. 2).

Given the same initial conditions (neuropsychological impairments and a history of failure, underachievement, etc.) as shown in Fig. 1, but endowed with positive coping strategies and resources (e.g. resilience, creativity, CBTstrategies, etc.), the adult person with ADHD is confronted with a challenging situation. By being aware of her own resources and available coping strategies, a positive appraisal takes place. The person's self-esteem and selfefficacy are high, and she is confident of being capable to cope with the problem. Thus, the cognitions and beliefs have a positive connotation, which leads to positive emotions. These in turn influence the behaviour and applied coping strategies. Instead of avoidance and procrastination (Fig. 1), the person approaches the problem with the available coping strategies or searches for help if needed. This approach acquits itself as schema-non-confirming, as the person no longer avoids her quarrel with the problem. Accordingly, she may experience positive outcomes and the feeling of control.

Existing schemas/core beliefs (e.g. defectiveness, failure) can be macerated and re-evaluated through new experiences, and therefore more helpful schemas/core beliefs can be developed. Finally, the new schemas/core beliefs impact the exposure to the problem by fostering a positive appraisal of the self and one's own capacities to deal with challenging situations. This cycle can be described in terms of an upward spiral.

\section{Studies}

White and Shah (2006) carried out a study to understand creativity of ADHD individuals. Specifically, they were interested in inhibitory control and its significance in two aspects of creativity: convergent and divergent thinking. Convergent thinking describes the ability to constitute associations between dissimilar concepts (Mednick 1962). Guilford (1957) defined the ability to develop multiple ideas or solutions to a problem as divergent thinking. The results of this study suggested that adults with ADHD have higher divergent but lower convergent thinking ability compared to a non-ADHD group.

Reduced performance in convergent thinking may be attributed to ADHD-related deficits in inhibitory control. Highly creative people seem to have lower levels of executive inhibitory control and perform better on divergent thinking assignments than less creative individuals (Carson et al. 2003). Likewise, this finding seems to be applicable to adults with ADHD in real-life context (Weiss 
Fig. 2 A cognitive behavioural model of coping strategies and resources in adult ADHD (modified from Young and Bramham 2006 and Safren et al. 2005)

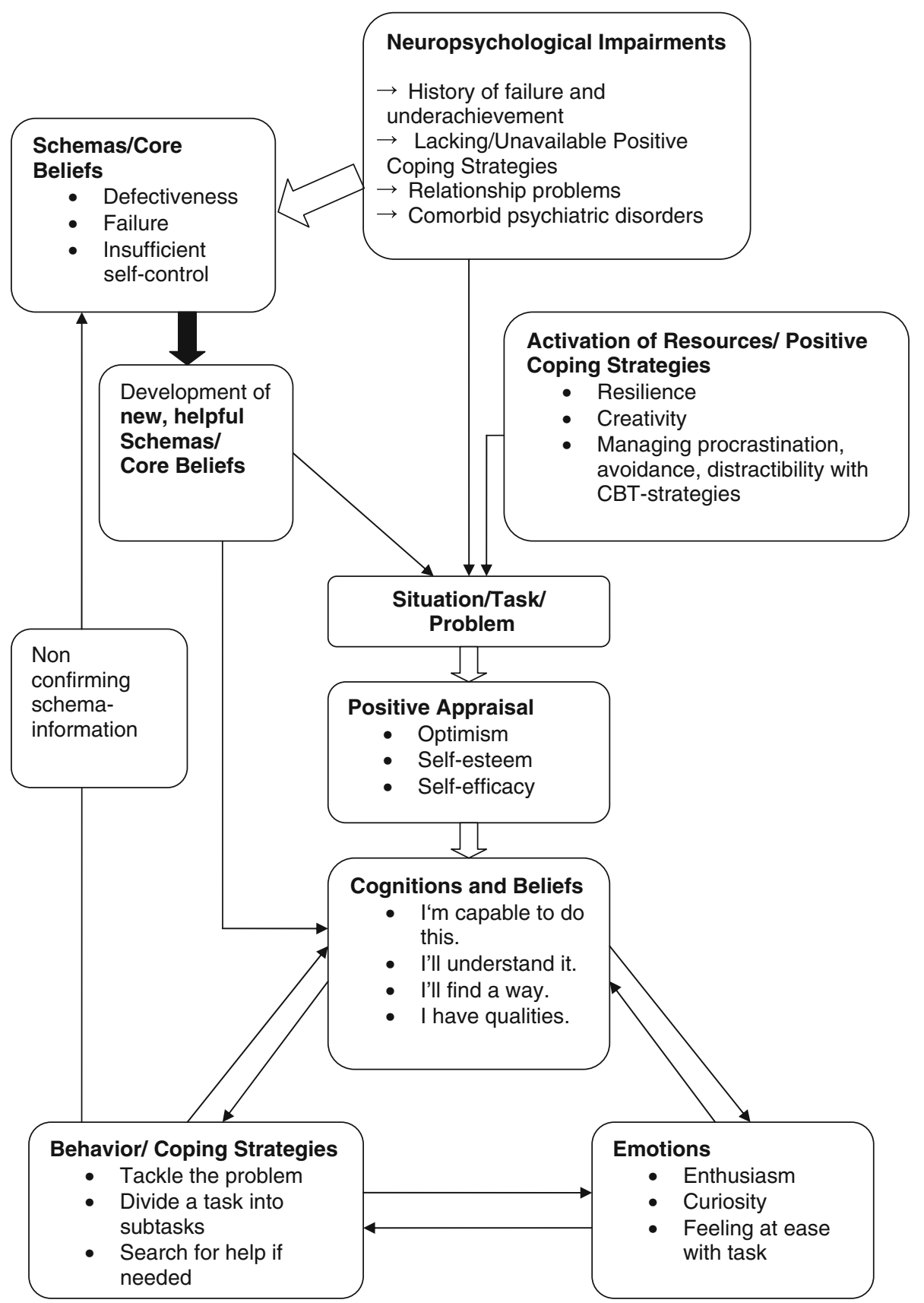

1997). However, some models of creativity suggest that both the ability of convergent and divergent thinking may be important for creative performance (Finke et al. 1992). Moreover, different subtypes of ADHD must be considered, as their creative magnitude may differ. Nigg et al. (2002) showed differences in inhibitory control as a function of ADHD subtypes. The limitation of these findings must be taken into account as there are currently no further studies (for Web search see methods section) investigating convergent/divergent thinking in adults with ADHD. Future research is needed to shed more light on the nature of creativity in adults with ADHD.
Another resource adults with ADHD typically possess is the ability to positively reappraise stressful situations (compare subsection on coping strategies: Relevance for adult ADHD). A positive association was found between this resilience and impulsivity. This may imply that impulsive individuals are less likely to cling to their problems and rather try to go ahead. Therefore, this trait may be highly beneficial for future problem-solving and helpful for therapy, as it is expected that their motivation to work on their difficulties does not decrease as easily after a setback. Even though the construct of resilience seems crucial in the treatment of adult ADHD, no specific studies 
were found with respect to resiliency in adult ADHD (for Web search see section on methods). The authors plan to conduct a study evaluating which resources are specific to adults with ADHD. However, further research on resources in adult ADHD is needed to improve psychotherapeutic methods for this disorder.

Specific therapeutic interventions and their significance

To foster resilience Ramsay and Rostain (2003), consider it to be important to keep the focus on relevant goals in one's life, without capitulating when confronted with setbacks. Likewise, in relapse prevention, it is useful to anticipate the interference or ambivalence the patient could encounter and to develop anticipatory responses. Patients are being prepared that they will continue to experience difficult situations after therapy, but they are also being advised that they have adopted skills to identify and develop helpful strategies.

In the final therapy sessions, Bramham and Young (2006) highlight the positive sides of having ADHD, namely creativity and resilience, and discuss how the patient can benefit from these internal resources in her life to achieve success (in short, medium, and long terms). Particularly important are the expectations of the self, which may influence future outcomes in terms of a selffulfilling prophecy.

For the purpose of developing a greater sense of selfefficacy in the patient, special attention is drawn to her past successes and achievements (compare interventions described in section on self-esteem), so that she can reappraise her capabilities. Future goals are then determined and put down on paper, considering that each goal needs to be broken down into small, achievable steps. The aim of this approach is to improve confidence in future successful performance. In the end, patients are prompted to assess external resources (social support system) outside of the therapeutic environment.

Barkley et al. (2009) also focus on external resources and recommend enlisting the assistance of personal coaches or mentors to help adults with ADHD manage their work and to enhance their performance on the job.

Regardless of whether the available resources of adults with ADHD are internal or external, in therapy, it is important to turn one's attention to the positive potential of the patient. The positive outcomes may be enhanced if these resources are additionally employed and fostered. In their study, Gassmann and Grawe (2006) showed that success in therapy depends on how strongly resources have been activated. Optimizing, invigorating, and maintaining internal and external resources is an important building block used in therapy (Flückinger and Wüsten 2008).

\section{Conclusions}

When looking at the various affected areas of life in individuals with ADHD, the need for an adequate treatment becomes obvious. Despite the fact that pharmacotherapy with methylphenidates is considered to be a highly effective intervention for reducing the core symptoms of adult ADHD (Faraone et al. 2004), not every individual tolerates this therapy, and the response rates are subject to strong variations (Sobanski and Alm 2004). Due to the severity and pervasiveness of this disorder, for up to $50 \%$ of the adults with ADHD pharmacotherapy may not fully address the multiple domains in which impairment is experienced (Wilens et al. 1997; Wilens et al. 2001). Significant functional problems in their lives as well as frequent comorbidity require adjunctive psychosocial interventions. Based on the recently growing empirical investigations, there is evidence that CBT-oriented psychosocial interventions in combination with medication may be an effective treatment or even the treatment of choice for adults with ADHD (Wiggins et al. 1999; Hesslinger et al. 2002; Safren et al. 2005; Ramsay and Rostain 2006.

The neuropsychological impairments caused by ADHD and the ongoing history of failure and underachievement have likely affected the belief system of the afflicted person. Emerging core beliefs/schemas can lead to maladaptive coping strategies that further deteriorate an individual's ability to handle adult ADHD and the related problems. Confronted with a difficult situation, the person enters the vicious cycle of negative appraisal. Numerous previous disappointments impact her self-esteem and selfefficacy. Negative cognitions may enhance negative emotions and lead to dysfunctional behaviour. Problems are being kept up, and the feeling of being unable to cope in an effective way acquits itself as schema-confirming. Breaking this cycle is crucial for the afflicted person as well as for the psychotherapeutic work. CBT may be the psychosocial treatment of choice for adults with ADHD, as it outlines the work on the belief system and the reciprocal influence of cognition, emotion, and behaviour.

Apart from the problem-orientated focus, the perception and acknowledgment of resources in adults with ADHD can be a relevant building block in therapy. Positive potential of the patient (e.g. resilience, creativity), once activated, is said to enhance the positive outcomes of psychotherapy. Fostering resources and positive coping strategies may help the patient deal with problems in a different, more optimistic, and helpful way.

The more the patient makes positive experiences, the more non-confirming schema information is generated (thus, positive beliefs about the self and the own abilities can be developed), and a positive feedback loop can be initiated. 
An important foundation for the treatment plan of adult ADHD may therefore implement work on the belief system and the reciprocal influence of cognition-emotion-behaviour in order to develop and practice effective coping strategies and to employ and foster personal resources. Further research needs to be done to define which CBT interventions are effective in treating the core and associated symptoms of adult ADHD and thus enhance the "positive cycle".

Acknowledgments This project was supported by the Swiss National Science Foundation, Grant No. 325100—120756/1.

\section{References}

Asendorpf JB (1996) Psychologie der Persönlichkeit. Grundlagen. Springer, Berlin

Bandura A (1997) The exercise of control. Freeman, New York

Bandura A (2002) Social cognitive theory in cultural context. J Appl Psychol 51:269-290

Barkley RA (2009) Attention deficit disorder in adults: the latest assessment and treatment strategies. Jones and Bartlett, Sudbury, MA

Beck AT (1963) Thinking and depression. Idiosyncratic content and cognitive distortions. Arch Gen Psychiatr 9:324-333

Beck AT (1967) Depression: clinical experimental and theoretical aspects. Harper \& Row, New York

Beck AT (1976) Cognitive therapy and the emotional disorders. Meridian, New York

Beck AT (1995) Cognitive therapy: basics and beyond. Guilford, New York

Beck AT, Rush AJ, Shaw BF, Emery G (1979) Cognitive therapy of depression. Guilford, New York

Biederman J (2004) Impact of comorbidity in adults with attentiondeficit/hyperactivity disorder. J Clin Psychiatr 65:3-7

Bramham J, Young S, Bickerdike A, Spain D, McCartan D, Xenitidis K (2009) Evaluation of group cognitive behavioral therapy for adults with ADHD. J Atten Disord 12:434-441

Burns DD (1980) Feeling good. Signet, New York

Carson SH, Peterson JB, Higgins DM (2003) Decreased latent inhibition is associated with increased creative achievement in high-functioning individuals. J Pers Soc Psych 85:499-506

Cohen S, Underwood LG, Gottlieb BH (2000) Social support measurement and intervention. Oxford University, New York

DeVellis BM, DeVellis RF (2000) Self-efficacy and health. In: Baum A, Revenson TA, Singer JE (eds) Handbook of health psychology. Erlbaum, Mahwah, NJ, pp 235-247

Faraone SV, Biederman J (2005) Adolescent predictors of functional outcome in adult ADHD: a population survey. Poster session presented at the 17th CHADD annual international conference, Dallas, TX

Faraone SV, Spencer TJ, Aleardi M, Pagano C, Biederman J (2004) Meta-analysis of the efficacy of methylphenidates for treating adult attention-deficit/hyperactivity disorder. J Clin Psychopharmacol 23:24-29

Finke FA, Ward TB, Smith SM (1992) Creative cognition: theory research and applications. MIT, Cambridge, MA

Flückinger C, Wüsten G (2008) Ressourcenaktivierung. Huber, Bern

Folkman S, Lazarus R (1980) An analysis of coping in a middle-aged community sample. J Health Soc Behav 21:219-239

Frank R (2007) Therapieziel Wohlbefinden. Springer, Berlin
Gassmann D, Grawe K (2006) General change mechanisms: the relation between problem activation and resource activation in successful and unsuccessful therapeutic interactions. Clin Psychol Psychother 13:1-11

Grawe K (1997) Research-informed psychotherapy. Psychother Res $7: 1-20$

Grawe K (1998) Psychologische therapie. Hogrefe, Göttingen

Guilford JP (1957) Creativity abilities in the arts. Psychol Rev 64:110-118

Hallowell EM, Ratey JJ (1994) Driven to distraction. Pantheon, New York

Hesslinger B, van Elst LT, Nyberg E et al (2002) Psychotherapy of attention deficit hyperactivity disorder in adults: a pilot study using a structured skills training program. Eur Arch Psychiatr Clin Neurosci 252:177-184

Holahan CJ, Moos RH (1987) Risk, resistance, and psychological distress: a longitudinal analysis with adults and children. J Abnorm Psychol 96:3-13

Hutchins DE, Vaught CC (1997) Helping relationships \& strategies, 3rd edn. Brooks/Cole, Pacific Grove, CA

Jerusalem M (1990) Persönliche ressourcen. Vulnerabilität und Stresserleben, Hogrefe, Göttingen

Jerusalem M, Schwarzer R (1992) Self-efficacy as a resource factor in stress appraisal processes. Hemisphere, Washington, DC

Karpel MA, Bauers WR (1986) Family resources. The hidden partner in family therapy, Guilford

Leskelä M, Vataja R, Grönroos N et al (2007) AD/HD-aikuisten psykologinen ryhmäkuntoutus-Vetäjän käsikirja. Rinnekoti Foundation, Espoo

Lopez SJ, Snyder CR (2004) Positive psychological assessment. APA, Washington

Luszczynska A, Diehl M, Gutiérrez-Doña B et al (2004) Measuring one component of dispositional self-regulation: attention control in goal pursuit. Person Ind Diff 37:555-566

Luszczynska A, Scholz U, Schwarzer R (2005) The general self-efficacy scale: multicultural validation studies. J Psychol 139:439-457

McDermott SP (1999) Cognitive therapy of attention deficit hyperactivity disorder in adults. J Cognit Psychother 13:215-226

McDermott SP (2000) Cognitive therapy for adults with attentiondeficit/hyperactivity disorder. In: Brown TE (ed) Attention deficit disorders and comorbidities in children, adolescents, and adults. American Psychiatric Press, Washington, DC, pp 569-606

Mednick SA (1962) The associative basis of the creative process. Psych Rev 69:220-232

Murphy KR (1998) Psychological counseling in adults with ADHD. In: Barkley RA (ed) Attention-deficit hyperactivity disorder: a handbook for diagnosis and treatment, 3rd edn. Guilford, New York, pp 582-591

Murphy KR, Gordon M (2006) Assessment of adults with ADHD. In: Barkley RA (ed) Attention-deficit hyperactivity disorder: a handbook for diagnosis and treatment, 3rd edn. Guilford, New York, pp 425-450

Neiss MB, Sedikides C, Stevenson J (2002) Self-esteem: a behavioural genetic perspective. Eur J Pers 16:1-17

Nestmann F (1996) Psychosoziale Beratung - ein ressourcentheoretischer Entwurf. Verhaltensther Psychosoz Praxis 28:359-376

Nigg JT, Blaskey LG, Huang-Pollack CL et al (2002) Neurological executive functions and DSM-IV ADHD subtypes. J Am Acad Child Adolesc Psychiatr 41:59-66

Philipsen A, Richter H, Peters J et al (2007) Structured group psychotherapy in adults with attention deficit hyperactivity disorder. Results of an open multicentre study. J Nerv Ment Dis 195:1013-1019

Piaget J (1948) The moral judgement of the child. Free, Glencoe, IL 
Ramsay JR, Rostain AL (2003) A cognitive therapy approach for adult attention-deficit/hyperactivity disorder. J Cognit Psychother Int Q 17:319-334

Ramsay JR, Rostain AL (2005) Adapting psychotherapy to meet the needs of adults with attention-deficit disorder. Psychother Theory Res Pract Train 42:72-84

Ramsay JR, Rostain AL (2006) Cognitive behaviour therapy for college students with attention-deficit/hyperactivity disorder. J Coll Stud Psychother 21:3-20

Ramsay JR, Rostain AL (2008) Adult ADHD. Routledge, Taylor \& Francis Group, New York

Rosenberg M (1965) Society and the adolescent self-image. Princeton University, Princeton, NJ

Rosenberg M (1979) Conceiving the self. Basic Books, New York

Safren SA (2006) Cognitive-behavioral approaches to ADHD treatment in adulthood. J Clin Psychiatr 67:46-50

Safren SA, Sprich S, Chulvick S et al (2004) Psychosocial treatments for adults with attention-deficit/hyperactivity disorder. Psychiatr Clin North Am 27:349-360

Safren SA, Otto MW, Sprich S et al (2005) Cognitive-behaviour therapy for ADHD in medication-treated adults with continued symptoms. Behav Res Ther 43:831-842

Schwarzer R, Jerusalem M (1989) Erfassung leistungsbezogener und allgemeiner Kontroll- und Kompetenzerwartungen. In: Krampen G (ed) Diagnostik von Attributionen und Kontrollüberzeugungen. Hogrefe, Göttingen, pp 127-133

Schwarzer R, Jerusalem M (1995) Generalized Self-Efficacy scale. In: Weinman J, Wright S, Johnston M (eds) Measures in health psychology. A user's portfolio. Casual and control beliefs. NFER-Nelson, Windsor

Shekim W, Asarnow RF, Hess E et al (1990) An evaluation of attention deficit disorder-residual type. Compr Psychiatr 31:416425

Sherer M, Maddux JE, Mercadante B et al (1982) The self-efficacy scale: constructions and validation. Psychol Rep 51:663-671

Sobanski E, Alm B (2004) Aufmerksamkeitsdefizit/Hyperaktivitätsstörung bei Erwachsenen. Nervenarzt 75:697-716
Stevenson CS, Withmont S, Bornholt L et al (2002) A cognitive remediation programme for adults with attention deficit hyperactivity disorder. Aust New Zeal J Psychiatr 36:610-616

Stevenson CS, Stevenson RJ, Withmore S (2003) A self-directed psychosocial intervention with minimal therapist contact for adults with attention deficit hyperactivity disorder. Clin Psychol Psychother 10:93-101

Virta M, Vedenpaa A, Gronroos N et al (2008) Adults with ADHD benefit from cognitive-behaviourally oriented group rehabilitation: a study of 29 participants. J Attention Disorders 12:218 226

Weiss L (1997) ADD and creativity: tapping your inner muse. Taylor Trade Publishing, Lanham

Wender EH (1995) Attention-deficit hyperactivity disorders in adolescence. J Dev Behav Pediatr 16:192-195

White HA, Shah P (2006) Uninhibited imaginations: creativity in adults with attention-deficit/hyperactivity disorder. Pers Indiv Differ 40:1121-1131

Wiggins D, Singh K, Getz HG et al (1999) Effects of brief group intervention for adults with attention deficit/hyperactivity disorder. J Ment Health Counsel 21:82-92

Wilens TE, Biederman J, Mick E et al (1997) Attention deficit hyperactivity disorder (ADHD) is associated with early onset substance use disorders. J Nerv Ment Dis 183:48-50

Wilens TE, Spencer TJ, Biederman J (2001) A controlled clinical trial of bupriopion for attention-deficit/hyperactivity disorder in adults. Am J Psychiatr 158:282-288

Wilens TE, Biederman J, Spencer TJ (2002) Attention deficit/ hyperactivity disorder across the lifespan. Annu Rev Med 53:113-131

Young S (2005) Coping strategies used by adults with ADHD. Pers Indiv Differ 38:809-816

Young S, Bramham J (2006) ADHD in adults. A psychological guide to practice. Wiley, Ltd, The Atrium

Young JE, Klosko JS, Weishaar ME (2003) Schema therapy. A practitioner's guide, Guilford 